\title{
Sex and gender in asthma
}

\author{
Nowrin U. Chowdhury $\mathbb{1}^{1,3,5}$, Vamsi P. Guntur $\mathbb{1}^{2,3,5}$, Dawn C. Newcomb ${ }^{1,4}$ and Michael E. Wechsler ${ }^{2,3}$ \\ Number 3 in the Series "Sex and gender in lung disease" \\ Edited by Jason Weatherald, Marc Humbert and Renata Riha
}

${ }^{1}$ Dept of Pathology, Microbiology, and Immunology, Vanderbilt University, Nashville, TN, USA. ${ }^{2}$ Division of Pulmonary, Critical Care, and Sleep Medicine, National Jewish Health, Denver, CO, USA. ${ }^{3}$ The NJH Cohen Family Asthma Institute, Denver, CO, USA. ${ }^{4}$ Dept of Medicine, Vanderbilt University Medical Center, Nashville, TN, USA. ${ }^{5}$ Equal contribution to first authorship.

Corresponding author: Dawn C. Newcomb (dawn.newcomb@vumc.org)

Shareable abstract (@ERSpublications)
Dysanaptic lung growth through life, and hormonal and genetic differences affect phenotypic
manifestations of asthma and response to therapy between males and females. These sex and
gender differences in asthma are discussed in this article. https://bit.ly/3xkaiPW
$\begin{aligned} & \text { Check for } \\ & \text { updates }\end{aligned}$
Cite this article as: Chowdhury NU, Guntur VP, Newcomb DC, et al. Sex and gender in asthma. Eur
Respir Rev 2021; 30: 210067 [DOI: $10.1183 / 16000617.0067-2021]$.
Respir Rev 2021; 30: 210067 [DOI: 10.1183/16000617.0067-2021].

\section{Copyright (The authors 2021}

This version is distributed under the terms of the Creative Commons Attribution NonCommercial Licence 4.0. For commercial reproduction rights and permissions contact permissions@ersnet.org

Received: 10 March 2021 Accepted: 26 June 2021

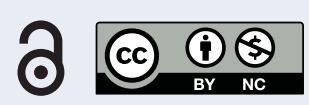

\section{Abstract}

Asthma is a heterogenous disease, and its prevalence and severity are different in males versus females through various ages. As children, boys have an increased prevalence of asthma. As adults, women have an increased prevalence and severity of asthma. Sex hormones, genetic and epigenetic variations, social and environmental factors, and responses to asthma therapeutics are important factors in the sex differences observed in asthma incidence, prevalence and severity. For women, fluctuations in sex hormone levels during puberty, the menstrual cycle and pregnancy are associated with asthma pathogenesis. Further, sex differences in gene expression and epigenetic modifications and responses to environmental factors, including SARS-CoV-2 infections, are associated with differences in asthma incidence, prevalence and symptoms. We review the role of sex hormones, genetics and epigenetics, and their interactions with the environment in the clinical manifestations and therapeutic response of asthma.

\section{Overview of sex and gender in asthma}

Asthma prevalence ranges from as low as $1 \%$ in some countries to as high as $18 \%$ in others, with a total of more than 339 million people with asthma worldwide. There is a clear sex disparity in asthma. While there is a higher preponderance of asthma in boys under age 13 (65\% prevalence), rates are higher (65\% prevalence) in adult women compared with men (figure 1) [1, 2]. This shift in asthma prevalence in males and females over time suggests a role of sex hormones and a complex interplay of socioeconomic factors, differential access to resources (e.g. nutrition and air quality), comorbidities and healthcare in developing versus developed countries (figure 2). Underpinning all these factors are genetic variations, including gene expression and epigenetic modifications, between males and females with asthma [3-5]. Throughout their lifetime, females have a higher likelihood of developing asthma and developing a more severe form of asthma than their male counterparts [6]. In developed countries, higher healthcare utilisation correlates directly with higher prevalence in the varying age categories (higher in boys aged 2-13 years and women 23-64 years) [2].

Asthma is a heterogenous disease with different phenotypes and responses to current therapeutics. Multivariate cluster analyses on adults with asthma or controls determined that different phenotypes of asthma require different utilisation of primary or secondary healthcare. Sex differences are seen in these various clusters, with female predominance in less atopic, less corticosteroid responsive patients, and in obese patients with steroid refractory asthma [7, 8]. Prior studies also showed, using cluster analysis based on utilisation of primary and secondary healthcare for asthma, that a female predominance is seen in clusters that have increased asthma symptoms and utilisation of care for eosinophil-driven asthma [9]. Yet, 


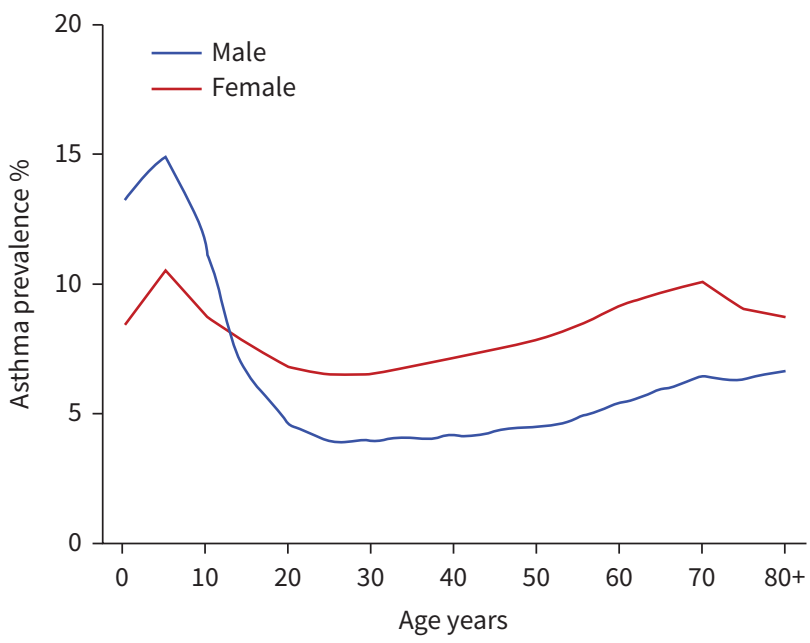

FIGURE 1 Asthma prevalence percentage throughout life in developed countries. Graph based on 2018 data from the Global Health Data Exchange (https://ghdx.healthdata.org).

these cluster analysis studies also showed that men have increased prevalence in severe asthma that is associated with nasal polyps or with environmental exposures including cigarette smoke or diesel exhaust [8]. Combined, these clustering studies demonstrate the complexity of asthma and the many different phenotypes.

Immune mechanisms associated with different asthma phenotypes are shown in figure 3. Type 2 (T2) asthma is often characterised by allergies and/or inflammation consisting of production of interleukins (IL) IL-4, IL-5, IL-13 and IL-9 from type 2 innate lymphoid cells (ILC2s), and/or CD4+ T-helper type 2 cells (Th2). The increased production of type 2 cytokines leads to increased IgE, mast cell activation, mucus and exhaled nitric oxide fraction $\left(F_{\mathrm{ENO}}\right)$ production, eosinophil infiltration and activation and airway hyperresponsiveness (AHR). Non-T2 inflammation is present in some endotypes of asthma with increased neutrophil infiltration, mucus production and AHR that is mediated by increased interferon

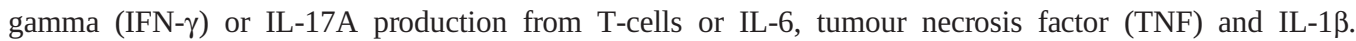
Children with asthma primarily manifest the T2 eosinophilic or allergic asthma phenotypes, but children with asthma also have increased association with genes important in the IFN- $\gamma$ signalling pathways [10].

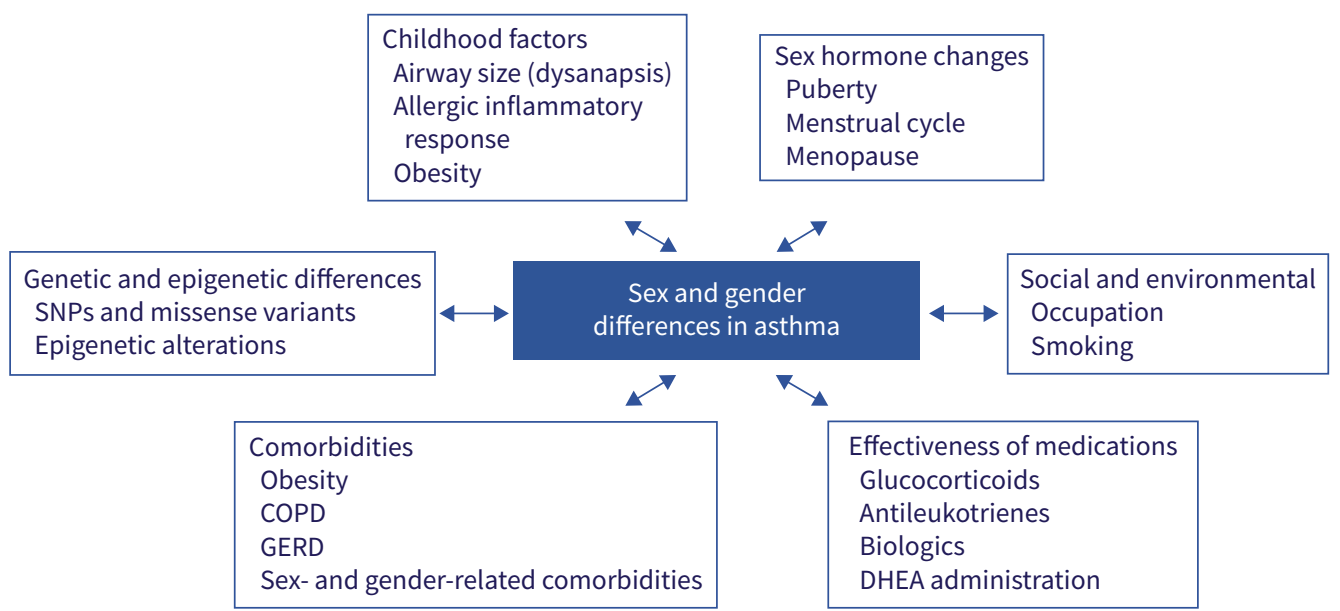

FIGURE 2 Sex and gender differences in asthma are influenced by several factors that vary across the lifespan. As shown by bi-directional arrows, these factors affect the sex and gender differences observed in asthma or are affected by sex hormones. DHEA: dehydroepiandrosterone; GERD: gastro-oesophageal reflux disease; SNP: single nucleotide polymorphism. 


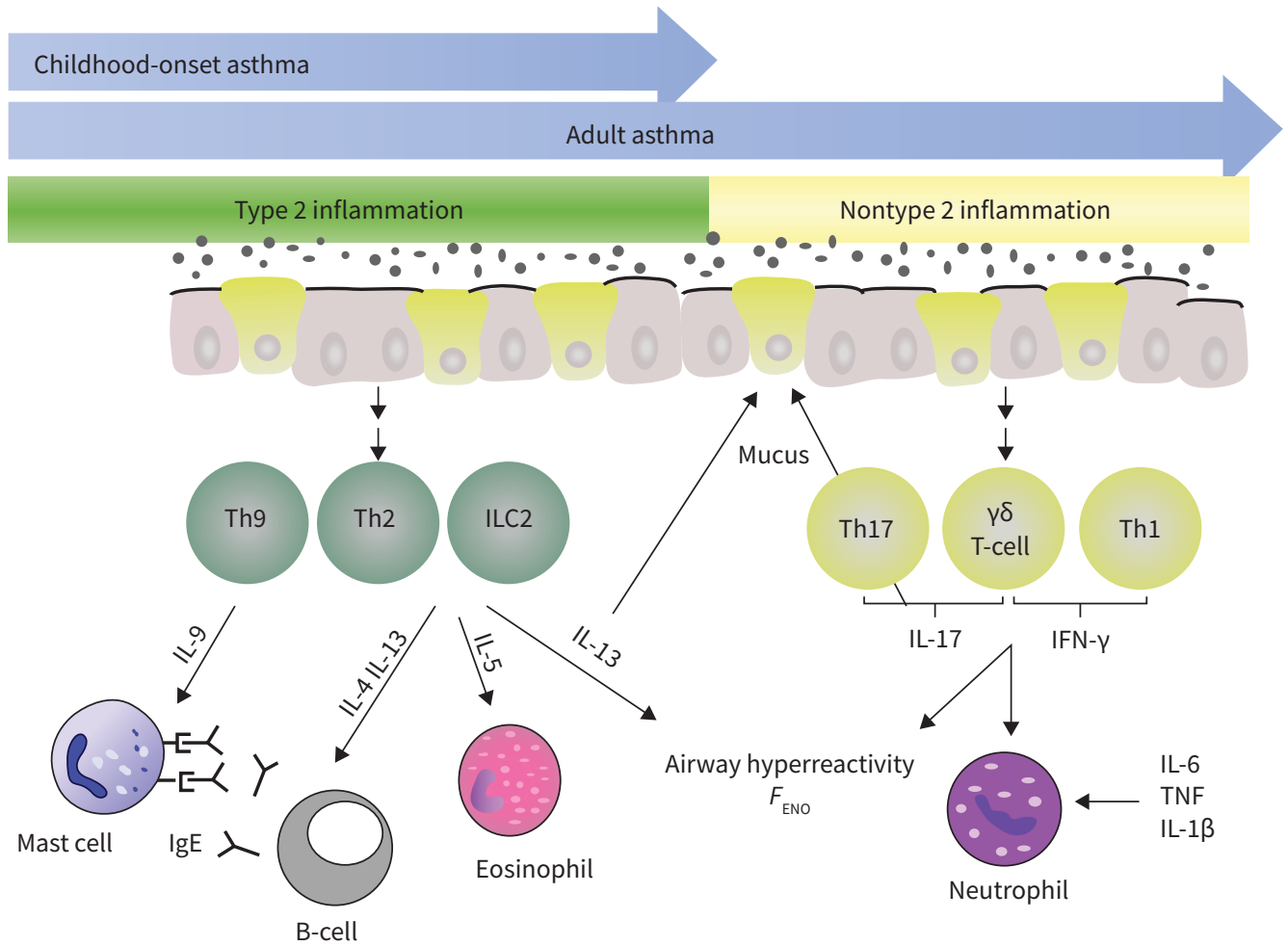

\begin{tabular}{|c|c|c|}
\hline \multicolumn{3}{|c|}{ Summary of in vivo mouse model results } \\
\hline & Type 2 inflammation & IL-17A-mediated inflammation \\
\hline ER- $\alpha$ signalling & $\begin{array}{l}\uparrow \mathrm{AHR} \\
\uparrow \mathrm{IL}-33 \text { production and release to } \\
\text { increase type } 2 \text { inflammation } \\
\uparrow \mathrm{M} 2 \text { macrophages }\end{array}$ & $\begin{array}{l}\uparrow \text { IL-17A production } \\
\uparrow \text { neutrophil infiltration, AHR and mucus } \\
\text { production }\end{array}$ \\
\hline ER- $\beta$ signalling & $\downarrow$ AHR, eosinophil infiltration & \\
\hline AR signalling & $\begin{array}{l}\downarrow \text { ILC2 proliferation and cytokine expression } \\
\text { } \text { Eosinophils, AHR, mucus, IgE, IL-5 and } \\
\text { IL-13 cytokine production } \\
\downarrow \text { IL-33 and TSLP production }\end{array}$ & $\begin{array}{l}\downarrow \text { IL-17A production } \\
\downarrow \text { neutrophil infiltration, AHR and mucus } \\
\text { production }\end{array}$ \\
\hline
\end{tabular}

FIGURE 3 Mechanisms driving airway inflammation in asthma pathogenesis. Type 2 (green) and nontype 2 (yellow) adaptive immune responses associated with asthma pathogenesis. This cartoon shows how increased activation and differentiation of type 2 responses leads to increased IL-4, IL-5, IL-9 and IL-13 production as well as increased eosinophil infiltration, B-cell production of IgE, AHR, $F_{\text {ENO }}$ and mucus production. Nontype 2 inflammation is more commonly seen in adults than children with asthma. Nontype 2 inflammation results in increased production of IL-17A or IFN- $\gamma$ from T-cells or increased IL-6, TNF and IL-1 $\beta$ leading to increased neutrophil infiltration, AHR, $F_{\mathrm{ENO}}$ and mucus production. AHR: airway hyperresponsiveness; $F_{\mathrm{ENO}}$ : exhaled nitric oxide fraction; IFN: interferon; IL: interleukin; ILC2: type 2 innate lymphoid cell; Th: T-helper cell; TNF: tumour necrosis factor; TSLP: thymic stromal lymphopoietin.

T2, non-T2 or mixed endotypes of asthma are seen among adults. As summarised in the chart at the bottom of figure 3 and in prior publications, oestrogen signalling through oestrogen receptor (ER)- $\alpha$ increased AHR, IL-33 production, type 2 cytokine production and eosinophil infiltration into the airway while oestrogen signalling through ER- $\beta$ decreased AHR and eosinophil infiltration [11-13]. Testosterone and other androgens signalling through the androgen receptor (AR) decreased ILC2 proliferation, eosinophil infiltration, IL-33 and thymic stromal lymphopoietin (TSLP) production, and type 2 cytokine production [11, 12, 14-16]. 
Environmental factors and exposures interact with airway architecture, immunology and hormones and thus contribute to sex and gender differences worldwide. The economy, geography, pre-morbid vaccinations, maternal parity, breastfeeding, environmental smoke and pollution, urbanisation and other factors contribute to the balance between T2-mediated and non-T2 mediated inflammation. Yet, how these enviromental factors differentially effect $\mathrm{T} 2$ and non-T2-mediated inflammation in males and females with asthma is understudied [17-25]. Further, fixed airway obstruction is also observed in more severe phenotypes of asthma in adults and is more prevalent in males compared with females [26-31]. Persistent, irreversible or fixed airflow obstruction (FAO) may ensue in 50\% of people with asthma [26, 27], proposed to be from impaired airway smooth muscle [28] and abnormal response to steroids and/or $\beta$-2-agonist therapy. FAO may be associated with male gender in both younger and older people with asthma [26, 27, 29]. The younger FAO asthmatic group represented more atopy and steroid resistance than their elder male counterparts. Two FAO endotypes (eosinophilic and neutrophilic) were identified, suggesting a complex relationship of FAO to asthma severity and medication response, beyond gender [30]. This review specifically discusses the role of sex hormones and genetics, and their interaction with the environment in the clinical manifestation and therapeutic response in asthma.

\section{Sex differences in childhood asthma}

Childhood differences in asthma manifestation between boys and girls is traced back to fetal and post-natal lung development $[17,32,33]$. Dysanaptic lung development, a mismatch between the size of the airway tree and lungs, in relation to airway flow rates was first described by MEAD in 1980 and noticed most prominently in boys compared with girls [34]. Dysanapsis was also described in adult women compared with men, and dysanapsis was found to be exacerbated by obesity in women and children [35]. Obese women and children manifested lower flow rates for a given vital capacity, a correlate of lung size [34]. Dysanaptic lung growth does not correlate with methacholine-induced AHR but could correlate with allergen sensitisation [36]. In boys $(n=149)$ and girls $(n=66)$ aged less than 13 years from South Korea, increased AHR was independently associated with mould sensitisation or increased blood eosinophil counts only in the boys [37]. In addition to boys having higher IgE levels than their counterparts [38], pre-puberty versus late-puberty boys demonstrate increased dehydroepiandrosterone sulfate (DHEA-S) with a positive correlation with forced expiratory volume in the first second $\left(\mathrm{FEV}_{1}\right)$ percentage, that is different from the negative correlation observed in girls [39]. These differences were apparent despite correction for body mass index (BMI) and steroid use. Differences in detected higher atopy, higher IgE levels and DHEA-S-mediated improvement in $\mathrm{FEV}_{1}$ percentage are interlinked with the dysanaptic hypothesis proposed decades ago occurring in boys compared with girls during the late- or post-pubertal years.

\section{Sex hormones in asthma}

Sex hormones are key mediators of the transition of differences in asthma prevalence across sexes from childhood into adulthood. As shown in figure 1, these changes occur during adolescence and result in higher prevalence of asthma in adult women compared with adult men.

\section{Menstruation and asthma}

Oestrogen and progesterone fluctuate during the menstrual cycle, peaking in the late follicular and midluteal phases. Decreased $\mathrm{FEV}_{1}$ and forced vital capacity (FVC), increased AHR and increased asthma-related healthcare utilisation have been noted during the luteal phase [40-42]. Early studies showed that $20-40 \%$ of women with asthma had increased symptoms during the pre- and peri-menstrual period with associated decreases in peak expiratory flow rates [43-48]. In the Severe Asthma Research Program (SARP) cohort, women with pre- and peri-menstrual asthma (PMA) had increased hospitalisation, healthcare utilisation, and use of oral corticosteroids compared with women who did not have PMA [41, 44]. During the premenstrual phase, studies have shown that patients had increased sputum eosinophils and $F_{\text {ENO }}$ compared with after menses $[49,50]$ as well as higher aspirin sensitivity [51]. Expanding upon this, EID et al. recently showed that $24 \%$ of women with aspirin-exacerbated respiratory disease (AERD) had PMA [52]. Patients with AERD-associated PMA had increased emergency department visits and hospitalisations but no differences in asthma medications, baseline $\mathrm{FEV}_{1} \%$ predicted (\% pred), or Global Initiative for Asthma (GINA) scores [52]. These studies suggest hormone-dependent cyclic variations in asthma control and healthcare utilisation. However, other studies in women with or without self-reported PMA found no association with asthma and the menstrual cycle in terms of spirometry or airway reactivity [45, 47], emergency department visits or asthma-related events [53], timing of asthma exacerbations [53] or $F_{\mathrm{ENO}}$ and ventilation parameters [54]. While PMA clearly occurs in many women with asthma, additional research is needed to gain a better mechanistic understanding of this process and how it affects different women. 


\section{Pregnancy and asthma}

Changes in asthma control occur during pregnancy in 5-8\% of pregnant women in developed countries such as the United States but in up to 13\% worldwide [55-57]. Understanding these shifts in asthma control is essential for preventing adverse pregnancy outcomes, including pre-eclampsia, low birthweight, small sizes for gestational age and increased risk of newborn mortality [58-60], particularly in developing nations. In the 1980s, Schatz et al. reported that one-third of women with asthma had worsened symptoms, one-third had no change, and one-third had improvement of their asthma symptoms based on daily diaries and monthly spirometry [61]. In those who had worsened symptoms, patients returned to their pre-pregnancy lung function baseline by 3 months post-partum. However, these studies were conducted prior to defining various phenotypes and endotypes of asthma. Follow-up studies showed that women with more severe asthma were linked to worsening symptoms and increased exacerbations during pregnancy [62]. Continuation of asthma medication use during pregnancy showed no significant changes in asthma symptom score by interview-based data [63], further supporting the National Heart, Lung, and Blood Institute and GINA guideline recommendations to maintain asthma medication use during pregnancy. The Vitamin D Antenatal Asthma Reduction Trial (VDAART) had suggested a role of decreased vitamin D during early pregnancy as a contributor for poor asthma control based on an association of lower vitamin D levels in less controlled asthma [64, 65], but did not demonstrate an underlying mechanism to this association. Although we now know that prenatal vitamin D supplementation alone does not affect childhood asthma incidence [66], further study regarding the association of vitamin D and asthma in pregnancy is needed.

\section{Menopause and asthma}

During menopause, there is a large fluctuation in sex hormones and an increased number of comorbidities that have resulted in various findings from investigators on the effects of menopause on asthma prevalence and control. The Respiratory Health in Northern Europe (RHINE) study reported a new phenotype of asthma in a subset of women who have onset of disease after menopause [67, 68], and in the French E3N cohort, surgical menopause was associated with increased risk of asthma onset. The European Community Respiratory Healthy Survey I (ECRHS I) included 884 menopausal women (aged 46-54 years old, 540 using hormone replacement therapy (HRT)) and found no association in self-reported asthma and HRT use in pre-menopausal or post-menopausal women [69]. Yet in the ECRHS II trial, women going through menopause (amenorrhoeic for at least 6 months) had decreased lung function and had increased asthma symptoms compared with pre-menopausal patients [70].

Additional studies using the US Nurse's Health Study (NHS) cohort showed decreased asthma incidence in pre-menopausal women compared with post-menopausal women [71]. Consistent with the US NHS, severe asthma was more likely to occur in men than women in SARP study participants aged 45 or older, the opposite of what is observed in their younger adult counterparts [72]. In 2020, ScIoscia et al. demonstrated, in a cohort of 33 women diagnosed with post-menopausal asthma and 30 healthy menopausal controls, that with increasing asthma severity women had significantly increased circulating 17ß-oestradiol levels [73]. The relationship of menopause with asthma remains unclear, given that some women develop menopause-associated onset of asthma. Increased number of comorbidities and the use of HRT during menopause also confound this association.

The effect of HRT therapy during menopause on asthma risk and control has been studied in various cohorts. In the RHINE study, there was a significantly stronger association of asthma in lean $(\mathrm{BMI}<25)$ women taking HRT that was not seen in women on HRT with BMI > 25 [69]. Additionally, the US NHS showed increased risk of asthma incidence in ever use of HRT in a dose-dependent manner [71, 74]. Studies using the Explorys clinical registry with 1793810 women aged 50 or above or a Danish nested case-control study (229871 cases and 2250610 controls) showed that HRT was associated with increased asthma incidence and asthma prevalence [75, 76]. However, women from the Optimum Patient Care Database in the United Kingdom showed that any use of HRT was associated with reduced risk of asthma onset and longer duration of use was associated with a dose-response reduction of risk of asthma incidence [77]. It is unclear why HRT has varied responses on asthma risk and control, but other factors are certainly at play and additional studies are needed.

\section{Hormonal contraceptive use and asthma}

Menstrual cycle fluctuations in asthma symptoms occur in many women with asthma, and mechanistic studies showed that oestrogen and progesterone increased pathways important in asthma pathogenesis [12]. Therefore, use of hormonal contraceptives are likely to impact asthma incidence, prevalence and control. Data from 3257 premenopausal Scottish women showed that hormonal contraceptives reduced asthma incidence, decreased asthma-related healthcare utilisation, driven by a significant decrease in lean women [78], 
as well as decreased wheezing in asthma patients [79]. Recently, these results were verified in the Optimum Patient Care Research Database (a cohort of 564896 premenopausal women), showing that risk of asthma incidence is reduced by hormonal contraceptive use and duration of use [80, 81]. Combined, these studies showed hormonal contraceptives decrease asthma incidence and asthma symptoms, but additional research is also needed to determine the type of hormonal contraceptive that is most effective at reducing asthma incidence and symptoms.

\section{Androgens and asthma}

Androgens, such as testosterone or dehydroepiandrosterone (DHEA), reduce asthma incidence and may reduce asthma symptoms. Increased levels of DHEA in boys were associated with decreased risk of asthma risk in adolescents in the SARP paediatric cohort [39]. Additionally, decreasing testosterone levels in men older than 45 years was associated with increased asthma prevalence [82]. Participants with asthma aged 6-80 years old from the National Health and Nutrition Examination Survey $(n=7584)$, it was found that in both men and women greater than 12 years old, increased serum testosterone was associated with decreased asthma prevalence in a dose-dependent manner and was associated with increased $\mathrm{FEV}_{1}$ [83]. In another large cross-sectional study of 256219 adults aged 40-69 years old in the United Kingdom, increased free testosterone levels were significantly associated with decreased symptoms of asthma, decreased hospitalisations due to asthma in women, and decreased $\mathrm{FEV}_{1}$ and FVC in men [4].

The use of exogenous androgens reduced asthma burden. In a Phase II clinical trial, $70 \mathrm{mg}$ nebulised DHEA-S reduced Asthma Control Questionnaire (ACQ) scores of women with moderate-to-severe asthma compared with those who received placebo [84]. Further, orally administered DHEA increased FEV 1 compared with placebo in premenopausal mild-moderate asthmatic women with low baseline DHEA-S levels $\left(<200 \mu \mathrm{g} \cdot \mathrm{dL}^{-1}\right)$. No significant changes in $\mathrm{FEV}_{1}$ were observed between DHEA or placebo groups in women who had baseline DHEA-S $\geqslant 200 \mu \mathrm{g} \cdot \mathrm{dL}^{-1}$ [85].

\section{Sex-specific genetic and epigenetic differences in asthma}

Genetic variability has long been recognised as important in asthma pathogenesis, and researchers have linked over 200 genetic variations to asthma risk and severity [3, 86]. Sex-specific single nucleotide polymorphisms (SNPs) in genes or epigenetic variabilities in paediatric and adult asthma cohorts are described below and are summarised in table 1. SNPs in several genes important in initiating or sustaining T2 inflammation, including ORMDL3, TSLP, IL4RA and IL1RL1, have been implicated in asthma [3]. Polymorphisms in TSLP were linked to sex in the Costa Rican Childhood Asthma Management Program, California Children's Health Study, and Genomic Research on Asthma in the African Diaspora cohorts [87]. In these cohorts, TSLP SNP rs1837253 decreased asthma risk in males and TSLP SNP rs2289276 decreased asthma risk in females [87]. Sex-specific variations in interferon signalling, which is important for type 1 inflammation, were also associated with asthma in both paediatric and adult asthma cohorts. Using the Childhood Origins of Asthma (COAST) birth cohort at high-risk for asthma and allergic disease, IFNG SNPs rs2069727 heterozygosity in boys resulted in higher risk for asthma where the same SNP in girls had the lower risk [10]. Further, cord blood cells treated with lipopolysaccharide from the COAST cohort had increased IFN- $\gamma$ production only in girls heterozygous for rs2069727. Genome-wide genotype-by-sex interactions in asthma using the EVE Asthma Genetics Consortium also showed sex-specific associations with asthma in six genes with the strongest associations for SNPs in IRF1 in European Americans and RAP1GAP2 in Latino females. Interactions between these two SNPs and asthma were independently verified in a genome-wide association study (GWAS) and gene regulation studies [88]. Vitamin D signalling is also important for many immune processes, including airway inflammation associated with asthma. Vitamin D receptor polymorphisms were associated with females in both the Childhood Asthma Management Program paediatric cohort and in the US NHS longitudinal cohort of women [89]. These studies show that several sex-specific variations in immune pathways are important for asthma pathogenesis in children and adults.

Genetic variations in genes associated with pulmonary function are also sex specific. A variant in the $\beta 1$ subunit of the BK channel (KCNMB1 C818T), a $\mathrm{Ca}^{2+}$ and voltage-dependent potassium channel that is a negative regulator muscarinic receptor stimulated contraction, was associated with decreased $\mathrm{FEV}_{1} \%$ pred in African American men from the Study of Asthma, Genes and the Environment (SAGE) and the Chicago Initiative to Raise Asthma Health Equity (CHIRAH) asthma cohorts [90]. Additionally, $\beta 2$-adrenergic receptor polymorphisms were associated with wheeze and asthma in males before and after the onset of puberty in the Tucson Children's Respiratory Study cohort [91].

Genetic variations in pathways or signalling of oestrogen and androgens have also been associated with asthma. Oestrogen signals through the nuclear receptors, oestrogen receptor- $\alpha$ (ER- $\alpha$ ) and ER- $\beta$. In a 
TABLE 1 Factors impacting sex and gender difference in asthma

\begin{tabular}{|c|c|c|}
\hline Factor & Association by sex & Reference \\
\hline $\begin{array}{l}\text { Dysanapsis during } \\
\text { development }\end{array}$ & Increased risk in males & [34] \\
\hline \multicolumn{3}{|l|}{ SNPs in genes } \\
\hline \multirow[t]{2}{*}{ TSLP } & rs1837253 decreased asthma risk in males & [87] \\
\hline & s2289276 decreased asthma risk in females & [87] \\
\hline IFNG & $\begin{array}{l}\text { rs } 2069727 \text { heterozygosity increased risk in males but decreased } \\
\text { in females }\end{array}$ & [10] \\
\hline IRF1 & Increased risk in females & [88] \\
\hline RAP1GAP2 & Increased risk in females & [88] \\
\hline Vitamin D receptors & Increased risk in females & [89] \\
\hline KCNMB1 & Decreased $\mathrm{FEV}_{1}$ in males & [90] \\
\hline$\beta_{2}$-adrenergic receptor & Increased risk in males & [91] \\
\hline ESR1 & Increased risk & [92] \\
\hline HSD3B1 & Decreased responsiveness to therapeutics in females & [93] \\
\hline CpG methylation & Increased risk in females & {$[96]$} \\
\hline Obesity & Increased risk in females & {$[7,8,35]$} \\
\hline \multicolumn{3}{|l|}{ Environmental exposures } \\
\hline Cigarette smoke & $\begin{array}{l}\text { Increased risk in men but, when comparing within smokers, } \\
\text { increased risk in women }\end{array}$ & {$[8,120]$} \\
\hline Diesel & Increased risk in men & [8] \\
\hline Flour/baker products & Increased risk in men & [115] \\
\hline $\begin{array}{l}\text { Hair product-related } \\
\text { allergy }\end{array}$ & Increased risk in women & [115] \\
\hline $\begin{array}{l}\text { Wood or wood } \\
\text { component } \\
\text { dust }\end{array}$ & Increased risk in men & [115] \\
\hline Inorganic dust & $\begin{array}{l}\text { Increased risk of symptoms in women, decreased lung function } \\
\text { in men }\end{array}$ & [115] \\
\hline Cleaning products & No gender differences & {$[117]$} \\
\hline Ozone & Decreased lung function in women & {$[115,116]$} \\
\hline Healthcare utilisation & Increased risk in women & {$[99,101]$} \\
\hline Perception of asthma & Increased risk in women & {$[100,101]$} \\
\hline
\end{tabular}

phenome-wide association study (PheWAS), significant associations $(\mathrm{p}<0.05)$ between selected SNPs and asthma ICD-9 phecodes were observed. The rs1999805 SNP in ESR1, ER- $\alpha$, was significantly associated with increased asthma electronic health data from the Vanderbilt BioVU databank and UK BioBank [92]. HSD3B1 is an enzyme that converts DHEA to testosterone and a missense variant in HSD3B1(1245) was associated with glucocorticoid responsiveness in asthma. Women from the SARP I, II and III cohorts homozygous for HSD3B1(1245A), the restrictive allele preventing DHEA conversion into testosterone, had lower $\mathrm{FEV}_{1} \%$ pred on glucocorticoid therapies compared with patients not on glucocorticoids [93]. Combined, these data show sex-specific linkage in pathways important in asthma pathogenesis spans from childhood into adulthood.

Additional studies also determined that DNA methylation due to environmental exposures and sex hormones (at CpG motifs before and after puberty) are linked to asthma susceptibility [94-96], leading to a potential "switch" in asthma prevalence. CpG sites cg20891917 located on interferon-related developmental regulator 1 (IFRD1) were linked to sex-specific effects in asthma transition [96]. These data suggest that DNA methylation changes in puberty are important in post-pubertal asthma incidence. Additional research is needed to determine if DNA methylation alters mechanisms such as Th2 cell differentiation and cytokine production.

\section{Effectiveness of therapies}

Therapeutic interventions in asthma vary between males and females more often in adults than children. Sex differences in response to a variety of medications may be due to compliance, variability in airway size and flow, and hormonal or sex-based pharmacogenetic and pharmacokinetic differences. Many asthma treatments are targeted towards T2 inflammation (e.g. inhaled and systemic corticosteroids and biologics targeted at IL-4, IL-5 and IL-13), which has been shown to be less common in women compared with 
men [97, 98]. This could contribute to poorer control of asthma in women, regardless of treatment and compliance [99], and a more severe clinical manifestation or perception of asthma [100, 101].

Amongst inhalers, steroid-based therapies may be more effective among men [99], presumably due to some of the above described reasons. However, studies show discordant data in children, presumed to be affected by known inhaled corticosteroid (ICS) response, T2 inflammation, and/or differences in ethnicity [102-105]. Monotherapy is often initiated as first-line treatment for asthma in women; whereas combination therapy of ICS and long-acting $\beta$-agonist is used as first-line in men $[100,106]$. However, differences in sex-related long-acting $\beta$-agonist effectiveness in asthma were not found. Tiotropium, a long-acting muscarinic antagonist, did not distinguish its favourable effects between males and females [107]. Antileukotrienes are commonly used therapies in asthma, and antileukotrienes have better efficacy in women compared with men. Androgens attenuated the 5-lipoxygenase activating protein (FLAP), a protein required for the activation of 5-lipoxygenase and the production of leukotrienes, leading to a better response to antileukotrienes in women compared with men [108]. In children aged 2-9 years, boys treated with montelukast - an antagonist to the cysteinyl leukotriene type 1 receptor that inhibits the actions of cysteinyl leukotrienes - had decreased asthma symptoms compared with boys administered placebo control [109]. This was not seen in girls aged 2-9 years with no differences in asthma symptoms when administered montelukast or placebo control. These results are concordant with previously described androgen shifts with age.

Sex and gender differences in biologic asthma therapy have not been extensively studied. Retrospective analysis of anti-IgE treatment did not demonstrate difference between sexes in therapeutic response [110, 111]. Differences in response to other biologics such as anti-IL5 or anti-IL4 have not been studied.

Androgens and their precursors may be considered as targets for therapy. As described in the previous section, sulfonated DHEA (DHEA-S) levels are associated with $\mathrm{FEV}_{1}$, and women with low DHEA-S levels have greater risk for airflow limitation and asthma severity [85, 112]. DHEA-S levels, already low in women, can further be suppressed by systemic glucocorticoids [113], thereby potentially worsening asthma control [93]. Further, the variant of HSD3B1(1245A) is associated with glucocorticoid resistance, particularly in women [93]. Therefore, differential responses by sex are important in asthma anti-leukotriene and glucocorticoid use.

The effects of exogenous hormone on asthma symptomology and severity would best be studied in transgender patients receiving regular hormone therapy. However, there have not been extensive studies on asthma in this population. ZeIN et al. reported that in 7210 patients with gender dysphoria and 490 patients who underwent gender affirming surgery, asthma risk was highest in male to female transgender individuals but was also significantly increased in female to male transgender individuals [114]. Further studies in these populations would be beneficial in our understanding of the effects of sex hormones on disease.

Social and environmental factors

Sex and gender differences in environmental exposures and healthcare utilisation are important factors to consider in asthma as summarised in table 1. Occupational exposures to vapours, dust, and fumes exacerbate asthma and gender differences in occupational asthma vary by country and occupation. In the German Statutory Accident Insurance department 2017 report on occupational exposures that lead to allergic diseases, the most common occupational allergen exposure was to flour or flour/bakery products (baker's asthma), and this was disproportionally found in men (66\%) compared with women (34\%) [115]. Gender differences in other occupational allergens have also been observed: there is a higher prevalence of hair product-related allergy in women and wood or wood component dust in men. In ECRHS II, occupational exposures leading to new onset of asthma were similar in men and women [116]. However, in the United States, women are more likely to have occupational-related asthma compared with men [115]. These studies show that geographical and country differences in industry and industry standards affect gender differences in occupational asthma.

Gender differences in respiratory symptoms to various exposures have also been reported. Women are more likely to have shortness of breath and asthma when exposed to inorganic dust, while exposure to organic dust decreased lung function in men more than women [115]. Women are more likely to utilise cleaning and disinfecting products in the workplace. However, no gender differences in cleaning product-related asthma was determined in a recent systematic review [117]. Ozone exposure decreases lung function, induces AHR, and increases asthma symptoms in patients with asthma [118], and has a more pronounced effect on reducing $\mathrm{FEV}_{1}$ in women compared with men [119]. While men are more likely to smoke compared with women (22.8\% versus $18.3 \%)$, women who smoke have increased asthma and 
asthma symptoms [120]. Combined, these data show that gender should be considered in occupational exposures and the potential effect on asthma or respiratory symptoms.

COVID-19, sex/gender and asthma

SARS-CoV-2, the virus that is the cause of the COVID-19 pandemic, can give rise to a range of symptoms from a mild respiratory illness to severe multisystem disease and death. Sex and gender differences of asthma associated with SARS-CoV-2 infection are still unclear. Multiple studies have reported that although women have a similar rate of SARS-CoV-2 infections, men have a higher risk of more severe disease and hospitalisation [121-123]. One potential explanation for this sex difference in COVID-19 disease severity is variation in expression levels of ACE2, a receptor for the SARS-CoV-2 virus. An Australian group recently showed increased ACE2 gene expression level in older and male subjects and lower in people with asthma [124]. The SARP III cohort in the US also showed significantly increased expression of ACE2 in the sputum of men [125]. Several others have shown that ACE2 expression may be lower in children, IgE sensitised asthmatic subjects [126] and with IL-13 induction [127], without a known sex differentiation. Extrapolated from these data is the likelihood that T2 inflammation in asthma could be protective and result in less severe forms of COVID-19 [128]. CAmiolo et al. postulated the possibility that non-T2 asthma, particularly those with high IFN- $\gamma$, could be associated with increased risk for COVID-19 infection [129]. This is particularly interesting since non-T2 asthma is more commonly seen in women. Further investigation is needed regarding association of non-T2 asthma and COVID-19 infection, as many published papers suggesting that asthma is not a risk factor for COVID-19 infection do not distinguish between the two endotypes of asthma and their varying prevalence in men and women.

\section{Summary}

Asthma prevalence, incidence and severity are impacted by sex and gender differences in genetics/ epigenetics, sex hormones, social and environmental factors and response to therapeutics. Further, it is difficult to fully assess gender- and sex-specific risks in asthma due to confounding comorbidities. Higher asthma prevalence is associated with other diseases and disorders, including obesity, attention deficit/ hyperactivity disorder, and gastroesophageal reflux disease, as well as geographic location, socioeconomic status, pollutants, smoking, occupational exposures, race and ethnicity and many others. Although many large cohort studies, including SARP and ECHRS, attempt to control for these comorbidities by including the factors in their assessments and collecting data from a broad range of people, it would be difficult to attempt to correct for all confounding factors. Although more study of the correlation between genetic, environmental and hormonal differences between males and females is needed, a complex but relevant role of gene polymorphisms (e.g. rs1999805 in ESR1, HSD3B1(1245A)), sex hormones (e.g. oestrogen, ER- $\alpha$, testosterone, AR, DHEA-S)), and environmental factors (organic dust exposure, consequential DNA methylation) result in increased T2 inflammation and possibly worse AHR seen in males [11-16, 39, 82, 85, 92-96, 112, 115]. T2 asthma does appear to be more prevalent in pro-androgenic periods in both males and females (late-puberty boys, luteal phase in pre-menopausal women, post-menopause), with worse asthma possibly in low androgen states (low DHEA in late pubertal boys, low testosterone in adult men and women) [4, 39, 82, 83].

Response to therapy is also dependent on the complex interactions between these biologic processes. Mechanistic data in mouse models of asthma show that oestrogen signalling increased T2 or non-T2 inflammation and that androgens decreased T2 or non-T2 inflammation [12]. Therefore, additional clinical and epidemiological studies are needed to determine how changes in sex hormones or use of exogenous hormonal therapies alter asthma pathogenesis and response to current therapeutics. Further, with the additional approved biological therapies available for patients with asthma, it will be important to determine the efficacy of these therapeutics based on sex and gender at various ages. These studies will increase our understanding of asthma pathogenesis and provide personalised approaches for treating asthma through various reproductive stages of life.

Provenance: Commissioned article, peer reviewed.

Previous articles in this series: No. 1: Cheron C, McBride SA, Antigny F, et al. Sex and gender in pulmonary arterial hypertension. Eur Respir Rev 30: 2021; 200330. No. 2: LoMauro A, Aliverti A. Sex and gender in respiratory physiology. Eur Respir Rev 30: 2021; 210038.

Conflict of interest: N.U. Chowdhury reports support for the present manuscript from the National Institute of Health, who provided the following funding sources: T32GM007347. V.P. Guntur reports receiving support for attending meetings and/or travel from AstraZeneca and CASCADE Investigator meeting, outside the submitted 
work. D.C. Newcomb reports support for the present manuscript from National Institute of Health, who provided the following funding sources: HL122554, HL136664 and DK020593. M.E. Wechsler reports support for the present manuscript from the Jin Hua Foundation. Consulting fees were received outside the submitted work from AstraZeneca, Boehringer Ingelheim, Equillium, Genentech, GlaxoSmithKline, Novartis, Regeneron, RestorBio, Sanofi, Teva, Cohero Health and Pulmatrix.

Support statement: Funding was received from the National Institute of Health from the following funding sources: HL122554 (D.C. Newcomb), HL136664 (D.C. Newcomb), DK020593 (D.C. Newcomb) and T32GM007347 (N.U. Chowdhury). Funding was also received from AstraZeneca, GlaxoSmithKline, Teva Pharmaceutical Industries and Sanofi. Funding information for this article has been deposited with the Crossref Funder Registry.

\section{References}

1 GBD 2016 Disease and Injury Incidence and Prevalence Collaborators. Global, regional, and national incidence, prevalence, and years lived with disability for 328 diseases and injuries for 195 countries, 19902016: a systematic analysis for the Global Burden of Disease Study 2016. Lancet 2017; 390: 1211-1259.

2 Schatz M, Camargo CA Jr. The relationship of sex to asthma prevalence, health care utilization, and medications in a large managed care organization. Ann Allergy Asthma Immunol 2003; 91: 553-558.

3 El-Husseini ZW, Gosens R, Dekker F, et al. The genetics of asthma and the promise of genomics-guided drug target discovery. Lancet Respir Med 2020; 8: 1045-1056.

4 Han YY, Forno E, Celedon JC. Sex steroid hormones and asthma in a nationwide study of U.S. adults. Am J Respir Crit Care Med 2020; 201: 158-166.

$5 \quad$ Gomez JL. Epigenetics in asthma. Curr Allergy Asthma Rep 2019; 19: 56.

6 Wang $\mathrm{E}$, Wechsler ME, Tran TN, et al. Characterization of severe asthma worldwide: data from the international severe asthma registry. Chest 2020; 157: 790-804.

7 Moore WC, Bleecker ER, Curran-Everett D, et al. Characterization of the severe asthma phenotype by the National Heart, Lung, and Blood Institute's Severe Asthma Research Program. J Allergy Clin Immunol 2007; 119: 405-413.

8 Wu W, Bleecker E, Moore W, et al. Unsupervised phenotyping of Severe Asthma Research Program participants using expanded lung data. J Allergy Clin Immunol 2014; 133: 1280-1288.

9 Haldar P, Pavord ID, Shaw DE, et al. Cluster analysis and clinical asthma phenotypes. Am J Respir Crit Care Med 2008; 178: 218-224.

10 Loisel DA, Tan Z, Tisler CJ, et al. IFNG genotype and sex interact to influence the risk of childhood asthma. J Allergy Clin Immunol 2011; 128: 524-531.

11 Yung JA, Fuseini H, Newcomb DC. Hormones, sex, and asthma. Ann Allergy Asthma Immunol 2018; 120: 488-494.

12 Fuseini H, Newcomb DC. Mechanisms driving gender differences in asthma. Curr Allergy Asthma Rep 2017; 17: 19.

13 Ambhore NS, Kalidhindi RSR, Loganathan J, et al. Role of differential estrogen receptor activation in airway hyperreactivity and remodeling in a murine model of asthma. Am J Respir Cell Mol Biol 2019; 61: 469-480. Becerra-Diaz M, Strickland AB, Keselman A, et al. Androgen and androgen receptor as enhancers of M2 macrophage polarization in allergic lung inflammation. J Immunol 2018; 201: 2923-2933.

15 Blanquart E, Laffont S, Guery JC. Sex hormone regulation of innate lymphoid cells. Biomed J 2021; 44 144-156.

16 Blanquart E, Mandonnet A, Mars M, et al. Targeting androgen signaling in ILC2 s protects from IL-33-driven lung inflammation, independently of KLRG1. J Allergy Clin Immunol 2021; in press [https://doi.org/10.1016/j. jaci.2021.04.029].

17 Becklake MR, Kauffmann F. Gender differences in airway behaviour over the human life span. Thorax 1999; 54: 1119-1138.

18 Platts-Mills TA, Carter MC. Asthma and indoor exposure to allergens. N Engl J Med 1997; 336: 1382-1384.

19 von Mutius E, Martinez FD, Fritzsch C, et al. Skin test reactivity and number of siblings. BMJ 1994; 308: 692-695.

20 von Mutius E, Martinez FD, Fritzsch C, et al. Prevalence of asthma and atopy in two areas of West and East Germany. Am J Respir Crit Care Med 1994; 149: 358-364.

21 Wjst M, Dold S. Is asthma an endocrine disease? Pediatr Allergy Immunol 1997; 8: 200-204.

22 Burrows B, Barbee RA, Cline MG, et al. Characteristics of asthma among elderly adults in a sample of the general population. Chest 1991; 100: 935-942.

23 Bjorksten B. Allergy priming early in life. Lancet 1999; 353: 167-168.

24 Cookson WO, Moffatt MF. Asthma: an epidemic in the absence of infection? Science 1997; 275: 41-42.

25 Miles EA, Warner JA, Jones AC, et al. Peripheral blood mononuclear cell proliferative responses in the first year of life in babies born to allergic parents. Clin Exp Allergy 1996; 26: 780-788. 
Bennett GH, Carpenter L, Hao W, et al. Risk factors and clinical outcomes associated with fixed airflow obstruction in older adults with asthma. Ann Allergy Asthma Immunol 2018; 120: 164-168. e1.

Zhang L, He L, Gong J, et al. Risk factors associated with irreversible airway obstruction in asthma: a systematic review and meta-analysis. Biomed Res Int 2016; 2016: 9868704.

Rutting S, Xenaki D, Reddy KD, et al. Airway smooth muscle cells from severe asthma patients with fixed airflow obstruction are responsive to steroid and bronchodilator treatment in vitro. ERJ Open Res 2021; 7: 00117-2021.

Tashkin DP, Chipps BE, Trudo F, et al. Fixed airflow obstruction in asthma: a descriptive study of patient profiles and effect on treatment responses. J Asthma 2014; 51: 603-609.

Smith BM, Zhao N, Olivenstein R, et al. Asthma and fixed airflow obstruction: long-term trajectories suggest distinct endotypes. Clin Exp Allergy 2021; 51: 39-48.

Contoli M, Baraldo S, Marku B, et al. Fixed airflow obstruction due to asthma or chronic obstructive pulmonary disease: 5-year follow-up. J Allergy Clin Immunol 2010; 125: 830-837.

Lee A, Mathilda Chiu YH, Rosa MJ, et al. Prenatal and postnatal stress and asthma in children: temporaland sex-specific associations. J Allergy Clin Immunol 2016; 138: 740-747. e3.

Stick S. Pediatric origins of adult lung disease. 1 . The contribution of airway development to paediatric and adult lung disease. Thorax 2000; 55: 587-594.

Mead J. Dysanapsis in normal lungs assessed by the relationship between maximal flow, static recoil, and vital capacity. Am Rev Respir Dis 1980; 121: 339-342.

Forno E, Weiner DJ, Mullen J, et al. Obesity and airway dysanapsis in children with and without asthma. Am J Respir Crit Care Med 2017; 195: 314-323.

Munakata M, Ohe M, Homma Y, et al. Pulmonary dysanapsis, methacholine airway responsiveness and sensitization to airborne antigen. Respirology 1997; 2: 113-118.

Kim YH, Jang YY, Jeong J, et al. Sex-based differences in factors associated with bronchial hyperresponsiveness in adolescents with childhood asthma. Clin Exp Pediatr 2021; 64: 229-238.

Borish L, Chipps B, Deniz Y, et al. Total serum IgE levels in a large cohort of patients with severe or difficult-to-treat asthma. Ann Allergy Asthma Immunol 2005; 95: 247-253.

DeBoer MD, Phillips BR, Mauger DT, et al. Effects of endogenous sex hormones on lung function and symptom control in adolescents with asthma. BMC Pulm Med 2018; 18: 58.

Farha S, Asosingh K, Laskowski D, et al. Effects of the menstrual cycle on lung function variables in women with asthma. Am J Respir Crit Care Med 2009; 180: 304-310.

Rao CK, Moore CG, Bleecker E, et al. Characteristics of perimenstrual asthma and its relation to asthma severity and control: data from the Severe Asthma Research Program. Chest 2013; 143: 984-992.

Tan KS, McFarlane LC, Lipworth BJ. Loss of normal cyclical $\beta 2$ adrenoceptor regulation and increased premenstrual responsiveness to adenosine monophosphate in stable female asthmatic patients. Thorax 1997; 52: 608-611.

Agarwal AK, Shah A. Menstrual-linked asthma. J Asthma 1997; 34: 539-545.

Eliasson O, Scherzer HH, DeGraff AC Jr. Morbidity in asthma in relation to the menstrual cycle. J Allergy Clin Immunol 1986; 77: 87-94.

Gibbs CJ, Coutts II, Lock R, et al. Premenstrual exacerbation of asthma. Thorax 1984; 39: 833-836.

Juniper EF, Kline PA, Roberts RS, et al. Airway responsiveness to methacholine during the natural menstrual cycle and the effect of oral contraceptives. Am Rev Respir Dis 1987; 135: 1039-1042.

Pauli BD, Reid RL, Munt PW, et al. Influence of the menstrual cycle on airway function in asthmatic and normal subjects. Am Rev Respir Dis 1989; 140: 358-362.

Shames RS, Heilbron DC, Janson SL, et al. Clinical differences among women with and without self-reported perimenstrual asthma. Ann Allergy Asthma Immunol 1998; 81: 65-72.

Dweik RA, Boggs PB, Erzurum SC, et al. An official ATS clinical practice guideline: interpretation of exhaled nitric oxide levels $\left(F_{\mathrm{ENO}}\right)$ for clinical applications. Am J Respir Crit Care Med 2011; 184: 602-615.

Oguzulgen IK, Turktas H, Erbas D. Airway inflammation in premenstrual asthma. J Asthma 2002; 39: 517-522.

Suzuki K, Hasegawa T, Sakagami T, et al. Analysis of perimenstrual asthma based on questionnaire surveys in Japan. Allergol Int 2007; 56: 249-255.

2 Eid RC, Palumbo ML, Cahill KN. Perimenstrual asthma in aspirin-exacerbated respiratory disease. J Allergy Clin Immunol Pract 2020; 8: 573-578. e4.

Brenner BE, Holmes TM, Mazal B r, et al.. Relation between phase of the menstrual cycle and asthma presentations in the emergency department. Thorax 2005; 60: 806-809.

Nittner-Marszalska M, Dor-Wojnarowska A, Wolanczyk-Medrala A, et al. Studying allergic inflammation and spirometry over menstrual cycles in well-controlled asthmatic women: changes in progesterone and estradiol affect neither $F_{\text {ENO }}$ levels nor lung function. Nitric Oxide 2018; 75: 95-100.

Kwon HL, Triche EW, Belanger $\mathrm{K}$, et al. The epidemiology of asthma during pregnancy: prevalence, diagnosis, and symptoms. Immunol Allergy Clin North Am 2006; 26: 29-62. 
Mendola P, Laughon SK, Mannisto TI, et al. Obstetric complications among US women with asthma. Am J Obstet Gynecol 2013; 208: 127, e1-8.

Jolving LR, Nielsen J, Kesmodel US, et al. Prevalence of maternal chronic diseases during pregnancy - a nationwide population based study from 1989 to 2013. Acta Obstet Gynecol Scand 2016; 95: 1295-1304.

Bonham CA, Patterson KC, Strek ME. Asthma outcomes and management during pregnancy. Chest 2018; 153: 515-527.

Mendola P, Mannisto TI, Leishear K, et al. Neonatal health of infants born to mothers with asthma. J Allergy Clin Immunol 2014; 133: 85-90. e1-4.

Murphy VE, Schatz M. Asthma in pregnancy: a hit for two. Eur Respir Rev 2014; 23: 64-68.

Schatz M, Harden K, Forsythe A, et al. The course of asthma during pregnancy, post partum, and with successive pregnancies: a prospective analysis. J Allergy Clin Immunol 1988; 81: 509-517.

Schatz M, Dombrowski MP, Wise R, et al. Asthma morbidity during pregnancy can be predicted by severity classification. J Allergy Clin Immunol 2003; 112: 283-288.

Belanger K, Hellenbrand ME, Holford TR, et al. Effect of pregnancy on maternal asthma symptoms and medication use. Obstet Gynecol 2010; 115: 559-567.

Mirzakhani H, O'Connor G, Bacharier LB, et al. Asthma control status in pregnancy, body mass index, and maternal vitamin D levels. J Allergy Clin Immunol 2017; 140: 1453-1456.e7.

Jensen ME, Murphy VE, Gibson PG, et al. Vitamin D status in pregnant women with asthma and its association with adverse respiratory outcomes during infancy. J Matern Fetal Neonatal Med 2019; 32: 1820-1825.

Litonjua AA, Carey VJ, Laranjo N, et al. Six-year follow-up of a trial of antenatal vitamin D for asthma reduction. N Engl J Med 2020; 382: 525-533.

Balzano G, Fuschillo S, De Angelis E, et al. Persistent airway inflammation and high exacerbation rate in asthma that starts at menopause. Monaldi Arch Chest Dis 2007; 67: 135-141.

Triebner K, Johannessen A, Puggini L, et al. Menopause as a predictor of new-onset asthma: a longitudinal Northern European population study. J Allergy Clin Immunol 2016; 137: 50-57. e6.

Gomez Real F, Svanes C, Bjornsson EH, et al. Hormone replacement therapy, body mass index and asthma in perimenopausal women: a cross sectional survey. Thorax 2006; 61: 34-40.

Real FG, Svanes C, Omenaas ER, et al. Lung function, respiratory symptoms, and the menopausal transition. J Allergy Clin Immunol 2008; 121: 72-80.e3.

Troisi RJ, Willett WC, Weiss ST, et al. A prospective study of diet and adult-onset asthma. Am J Respir Crit Care Med 1995; 151: 1401-1408.

Zein JG, Dweik RA, Comhair SA, et al. Asthma is more severe in older adults. PLoS One 2015; 10: e0133490.

Scioscia G, Carpagnano GE, Lacedonia D, et al. The role of airways $17 \beta$-estradiol as a biomarker of severity in postmenopausal asthma: a pilot study. J Clin Med 2020; 9: 2037.

Barr RG, Wentowski CC, Grodstein F, et al. Prospective study of postmenopausal hormone use and newly diagnosed asthma and chronic obstructive pulmonary disease. Arch Intern Med 2004; 164: 379-386.

Zhang P, Zein J. Novel insights on sex-related differences in asthma. Curr Allergy Asthma Rep 2019; 19: 44.

Hansen ESH, Aasbjerg K, Moeller AL, et al. Women receiving hormone replacement therapy are at high risk of developing asthma. Eur Resp J 2020; 56: Suppl. 64, 1430.

Shah SA, Tibble H, Pillinger R, et al. Hormone replacement therapy and asthma onset in menopausal women: national cohort study. J Allergy Clin Immunol 2021; 147: 1662-1670.

Nwaru BI, Sheikh A. Hormonal contraceptives and asthma in women of reproductive age: analysis of data from serial national Scottish Health Surveys. J R Soc Med 2015; 108: 358-371.

Salam MT, Wenten M, Gilliland FD. Endogenous and exogenous sex steroid hormones and asthma and wheeze in young women. J Allergy Clin Immunol 2006; 117: 1001-1007.

Nwaru Bl, Pillinger R, Tibble $\mathrm{H}$, et al. Hormonal contraceptives and onset of asthma in reproductive-age women: population-based cohort study. J Allergy Clin Immunol 2020; 146: 438-446.

Nwaru BI, Tibble $\mathrm{H}$, Shah SA, et al. Hormonal contraception and the risk of severe asthma exacerbation: 17-year population-based cohort study. Thorax 76, 2021, 109-115.

Canguven O, Albayrak S. Do low testosterone levels contribute to the pathogenesis of asthma? Med Hypotheses 2011; 76: 585-588.

83 Bulkhi AA, Shepard KV 2nd, Casale TB, et al. Elevated testosterone is associated with decreased likelihood of current asthma regardless of sex. J Allergy Clin Immunol Pract 2020; 8: 3029-3035.e4.

Wenzel SE, Robinson CB, Leonard JM, et al. Nebulized dehydroepiandrosterone-3-sulfate improves asthma control in the moderate-to-severe asthma results of a 6-week, randomized, double-blind, placebo-controlled study. Allergy Asthma Proc 2010; 31: 461-471.

85 Marozkina N, Zein J, DeBoer MD, et al. Dehydroepiandrosterone supplementation may benefit women with asthma who have low androgen levels: a pilot study. Pulm Ther 2019; 5: 213-220.

Han Y, Jia Q, Jahani PS, et al. Genome-wide analysis highlights contribution of immune system pathways to the genetic architecture of asthma. Nat Commun 2020; 11: 1776. 

sex-specific fashion. Allergy 2010; 65: 1566-1575.

Myers RA, Scott NM, Gauderman WJ, et al. Genome-wide interaction studies reveal sex-specific asthma risk alleles. Hum Mol Genet 2014; 23: 5251-5259. childhood and adult asthma. Am J Respir Crit Care Med 2004; 170: 1057-1065.

90 Seibold MA, Wang B, Eng C, et al. An African-specific functional polymorphism in KCNMB1 shows sex-specific association with asthma severity. Hum Mol Genet 2008; 17: 2681-2690.

91 Guerra S, Graves PE, Morgan WJ, et al. Relation of $\beta 2$-adrenoceptor polymorphisms at codons 16 and 27 to persistence of asthma symptoms after the onset of puberty. Chest 2005; 128: 609-617.

Bloodworth $\mathrm{MH}$, Rusznak M, Bastarache $\mathrm{L}$, et al. Association of estrogen receptor alpha polymorphism rs1999805 with asthma. Ann Allergy Asthma Immunol 2019; 122: 208-210.

93 Zein J, Gaston B, Bazeley P, et al. HSD3B1 genotype identifies glucocorticoid responsiveness in severe asthma. Proc Natl Acad Sci USA 2020; 117: 2187-2193.

Joubert BR, Felix JF, Yousefi P, et al. DNA methylation in newborns and maternal smoking in pregnancy: genome-wide consortium meta-analysis. Am J Hum Genet 2016; 98: 680-696.

95 Joubert BR, Haberg SE, Nilsen RM, et al. $450 \mathrm{~K}$ epigenome-wide scan identifies differential DNA methylation in newborns related to maternal smoking during pregnancy. Environ Health Perspect 2012; 120: 1425-1431. Patel R, Solatikia F, Zhang $\mathrm{H}$, et al. Sex-specific associations of asthma acquisition with changes in DNA methylation during adolescence. Clin Exp Allergy 2021; 51: 318-328.

97 Senna G, Latorre M, Bugiani M, et al. Sex differences in severe asthma: results from Severe Asthma Network in Italy-SANI. Allergy, Asthma Immunol Res 2021; 13: 219-228.

98 Jensen ME, Gibson PG, Collins CE, et al. Airway and systemic inflammation in obese children with asthma. Eur Respir J 2013; 42: 1012-1019.

99 Dijkstra A, Vonk JM, Jongepier $\mathrm{H}$, et al. Lung function decline in asthma: association with inhaled corticosteroids, smoking and sex. Thorax 2006; 61: 105-110.

100 Colombo D, Zagni E, Ferri F, et al. Gender differences in asthma perception and its impact on quality of life: a post hoc analysis of the PROXIMA (Patient Reported Outcomes and Xolair((R)) In the Management of Asthma) study. Allergy Asthma Clin Immunol 2019; 15: 65.

101 To T, Gray N, Ryckman K, et al. Sex differences in health services and medication use among older adults with asthma. ERJ Open Res 2019; 5: 00242-2019.

102 Galant SP, Morphew T, Guijon O, et al. The bronchodilator response as a predictor of inhaled corticosteroid responsiveness in asthmatic children with normal baseline spirometry. Pediatr Pulmonol 2014; 49: 1162-1169.

103 Gerald JK, Gerald LB, Vasquez MM, et al. Markers of differential response to inhaled corticosteroid treatment among children with mild persistent asthma. J Allergy Clin Immunol Pract 2015; 3: 540-546.e3.

104 Szefler SJ, Phillips BR, Martinez FD, et al. Characterization of within-subject responses to fluticasone and montelukast in childhood asthma. J Allergy Clin Immunol 2005; 115: 233-242.

105 Wu YF, Su MW, Chiang BL, et al. A simple prediction tool for inhaled corticosteroid response in asthmatic children. BMC Pulm Med 2017; 17: 176.

106 Amegadzie JE, Gamble JM, Farrell J, et al. Gender differences in inhaled pharmacotherapy utilization in patients with obstructive airway diseases (OADs): a population-based study. Int J Chron Obstruct Pulmon Dis 2020; 15: 2355-2366.

107 Kerstjens HA, Moroni-Zentgraf P, Tashkin DP, et al. Tiotropium improves lung function, exacerbation rate, and asthma control, independent of baseline characteristics including age, degree of airway obstruction, and allergic status. Respir Med 2016; 117: 198-206.

108 Pace S, Pergola C, Dehm F, et al. Androgen-mediated sex bias impairs efficiency of leukotriene biosynthesis inhibitors in males. J Clin Invest 2017; 127: 3167-3176.

109 Johnston NW, Mandhane PJ, Dai J, et al. Attenuation of the September epidemic of asthma exacerbations in children: a randomized, controlled trial of montelukast added to usual therapy. Pediatrics 2007; 120: e702-e712.

110 Bousquet J, Cabrera P, Berkman N, et al. The effect of treatment with omalizumab, an anti-IgE antibody, on asthma exacerbations and emergency medical visits in patients with severe persistent asthma. Allergy 2005; 60: 302-308.

111 Viswanathan RK, Moss MH, Mathur SK. Retrospective analysis of the efficacy of omalizumab in chronic refractory urticaria. Allergy Asthma Proc 2013; 34: 446-452.

112 Pesce G, Triebner K, van der Plaat DA, et al. Low serum DHEA-S is associated with impaired lung function in women. EClinicalMedicine 2020; 23: 100389.

113 Dorsey MJ, Cohen LE, Phipatanakul W, et al. Assessment of adrenal suppression in children with asthma treated with inhaled corticosteroids: use of dehydroepiandrosterone sulfate as a screening test. Ann Allergy Asthma Immunol 2006; 97: 182-186. 
114 Zein JG, Denson JL, Wechsler ME. Asthma over the adult life course: gender and hormonal influences. Clin Chest Med 2019; 40: 149-161.

115 Moscato G, Apfelbacher C, Brockow K, et al. Gender and occupational allergy: report from the task force of the EAACI Environmental and Occupational Allergy Interest Group. Allergy 2020; 75: 2753-2763.

116 Kogevinas M, Zock JP, Jarvis D, et al. Exposure to substances in the workplace and new-onset asthma: an international prospective population-based study (ECRHS-II). Lancet 2007; 370: 336-341.

117 Folletti I, Zock JP, Moscato G, et al. Asthma and rhinitis in cleaning workers: a systematic review of epidemiological studies. J Asthma 2014; 51: 18-28.

118 Gent JF, Triche EW, Holford TR, et al. Association of low-level ozone and fine particles with respiratory symptoms in children with asthma. JAMA 2003; 290: 1859-1867.

119 Hazucha MJ, Folinsbee LJ, Bromberg PA. Distribution and reproducibility of spirometric response to ozone by gender and age. J Appl Physiol (1985) 2003; 95: 1917-1925.

120 Langhammer A, Johnsen R, Holmen J, et al. Cigarette smoking gives more respiratory symptoms among women than among men. The Nord-Trondelag Health Study (HUNT). J Epidemiol Community Health 2000; 54: $917-922$.

121 Lee SC, Son KJ, Han CH, et al. Impact of comorbid asthma on severity of coronavirus disease (COVID-19). Sci Rep 2020; 10: 21805.

122 Schonfeld D, Arias S, Bossio JC, et al. Clinical presentation and outcomes of the first patients with COVID-19 in Argentina: results of 207079 cases from a national database. PLoS One 2021; 16: e0246793.

123 Williamson EJ, Walker AJ, Bhaskaran K, et al. Factors associated with COVID-19-related death using OpenSAFELY. Nature 2020; 584: 430-436.

124 Wark PAB, Pathinayake PS, Kaiko G, et al. ACE2 expression is elevated in airway epithelial cells from older and male healthy individuals but reduced in asthma. Respirology 2021; 26: 442-451.

125 Peters MC, Sajuthi S, Deford P, et al. COVID-19-related genes in sputum cells in asthma. Relationship to demographic features and corticosteroids. Am J Respir Crit Care Med 2020; 202: 83-90.

126 Jackson DJ, Busse WW, Bacharier LB, et al. Association of respiratory allergy, asthma, and expression of the SARS-CoV-2 receptor ACE2. J Allergy Clin Immunol 2020; 146: 203-206.e3.

127 Kimura H, Francisco D, Conway M, et al. Type 2 inflammation modulates ACE2 and TMPRSS2 in airway epithelial cells. J Allergy Clin Immunol 2020; 146: 80-88.e8.

128 Ferastraoaru D, Hudes G, Jerschow E, et al. Eosinophilia in asthma patients is protective against severe COVID-19 illness. J Allergy Clin Immunol Pract 2021; 9: 1152-1162.e3.

129 Camiolo M, Gauthier M, Kaminski N, et al. Expression of SARS-CoV-2 receptor ACE2 and coincident host response signature varies by asthma inflammatory phenotype. J Allergy Clin Immunol 2020; 146: 315-324. e7. 